\title{
REFLETINDO SOBRE ALGUMAS TEORIAS DE ENFERMAGEM A PARTIR DO MODELO DE AVALIAÇÃO DE MELEIS
}

Talita Piccoli', Simony Fabiola Lopes Nunes', Priscilla Cibele Tramontina', Roberta Juliane Tono de Oliveira', Evanguelia Kotzias Atherino dos Santos², Lúcia Narazeth Amante ${ }^{2}$

${ }^{1}$ Enfermeira. Mestranda em Enfermagem. Universidade Federal de Santa Catarina. Florianópolis-SC-Brasil.

${ }^{2}$ Enfermeira. Doutora em Enfermagem. Professora da Universidade Federal de Santa Catarina. Florianópolis-SC-Brasil.

RESUMO: Este artigo teve como objetivo a realização de uma reflexão comparativa das teorias de enfermagem de Paterson e Zderad, Parse, Watson e Meleis, a partir do modelo de avaliação de teorias e seus componentes funcionais: foco, cliente, enfermagem, saúde, interação paciente-enfermagem, ambiente, problemas e cuidado de enfermagem proposto por Meleis. A escolha das teóricas justificou-se por serem teorias emergentes e que aderem ao paradigma atual, convergindo para visão holística do ser humano. Após reflexão teórica, concluiu-se que nas teorias analisadas a definição de enfermagem é clara e explícita, destacando sua ação na promoção da saúde e da qualidade de vida.

DESCRITORES: Teoria de enfermagem; Filosofia em enfermagem; Enfermagem.

\section{REFLECTING ON SOME NURSING THEORIES BASED ON MELEIS' EVALUATION MODEL}

\begin{abstract}
This article aimed to undertake a comparative reflection on the theories of nursing of Paterson and Zderad, Parse, Watson and Meleis, based on the theory evaluation model and its functional components: focus, client, nursing, health, patient-nursing interaction, environment, problems, and nursing care, as proposed by Meleis. The choice of the academic theorists was explained as these are emerging theories and adhere to the current paradigm, converging towards the holistic view of the human being. After theoretical reflection, it was concluded that, in the theories analyzed, the definition of nursing is clear and explicit, emphasizing its action in the promotion of health and quality of life.
\end{abstract}

DESCRIPTORS: Nursing theory; Philosophy in nursing; Nursing.

\section{REFLEXIONANDO ACERCA DE ALGUNAS TEORÍAS DE ENFERMERÍA CON BASE EN EL MODELO DE EVALUACIÓN DE MELEIS}

RESUMEN: Este artículo tuvo como objetivo la realización de una reflexión comparativa de las teorías de enfermería de Paterson e Zderad, Parse, Watson y Meleis, con base en el modelo de evaluación de teorías y sus componentes funcionales: foco, cliente, enfermería, salud, interacción paciente enfermería, ambiente, problemas y cuidado de enfermería propuesto por Meleis. La elección de las teorías se justificó en su emergencia y por adherir al paradigma actual, convergiendo para visión holística del ser humano. Después de la reflexión teórica, se concluyó que, en las teorías analizadas, la definición de enfermería es evidente y explícita, destacando su acción en la promoción de la salud y de la cualidad de vida.

DESCRIPTORES: Teoría de enfermería; Filosofía en enfermería; Enfermería. 


\section{INTRODUÇÃO}

Com a evolução da Enfermagem como ciência, os profissionais passaram a se questionar sobre a forma de utilização das práticas tradicionais, emergindo apontamentos que levaram ao desenvolvimento de um corpo de conhecimento específico como embasamento para o exercício da Enfermagem. Buscando atender esta necessidade, surgem as teorias de enfermagem, as quais proporcionaram o fortalecimento da disciplina no sentido de atuar de forma significativa na promoção, prevenção, recuperação e reabilitação da saúde. Esse corpo de conhecimento vem se transformando ao longo dos anos e assumindo modos de expressão diversos em sua trajetória de construção ${ }^{(1-2)}$.

Uma teoria é definida como articulação organizada e sistematizada de um conjunto de conceitos relacionados às questões de uma disciplina, fornecendo meios para conhecer a realidade concreta ${ }^{(3)}$. No que tange a enfermagem, a teoria é um conjunto de conceitos relacionados à realidade da enfermagem, seus fenômenos e a relação entre eles. As teorias servem para descrever, explicar, diagnosticar e prescrever medidas para a prática assistencial, oferecendo respaldo científico para as ações de enfermagem $^{(3-4)}$.

Entretanto, para responder a pertinência ou não de uma teoria no contexto da prática assistencial são utilizados os modelos de análise de teoria. Dos modelos existentes, destaca-se o Modelo de Avaliação de Teorias proposto por Meleis ${ }^{(3)}$, filosoficamente baseado em uma visão histórica de ciência, que contempla cinco segmentos para a análise: descrição, análise, crítica, teste e suporte.

Nesse estudo, a reflexão terá como foco o segmento descrição, por identificar os elementos conceituais centrais da teoria, através dos componentes funcionais: foco, cliente, enfermagem, saúde, interação pacienteenfermagem, ambiente, problemas de enfermagem e cuidado de enfermagem. Estes componentes devem estar claros e objetivos para que a proposta seja considerada uma teoria de enfermagem.

As teóricas escolhidas para este estudo apresentam teorias de enfermagem emergentes e que aderem ao paradigma atual, convergindo para visão holística do ser humano, cuidado humanístico, que vai além da concepção que saúde é apenas a ausência de doenças.

Neste contexto, o estudo é construto da disciplina Concepções Teórico-Filosóficas no Processo de Cuidar em Enfermagem e Saúde, do Mestrado Acadêmico, do Programa de PósGraduação em Enfermagem da Universidade Federal de Santa Catarina (PEN/UFSC), na área de concentração Filosofia e Cuidado em Saúde e Enfermagem, e teve por objetivo realizar uma reflexão comparativa entre a Teoria Humanística (1976), a Teoria Homem-Vida-Saúde (1987), Teoria do Cuidado Transpessoal (1988) e a Teoria das Transições (2010), utilizando os componentes funcionais, descritos segundo o Modelo de Avaliação de Teorias ${ }^{(3)}$.

\section{DESCRIÇÃO DOS COMPONENTES FUNCIONAIS DAS TEORIAS E APLICABILIDADE NA PRÁTICA DE ENFERMAGEM}

Josephine E. Paterson e Loretta T. Zderad publicaram a Teoria Humanística em 1976, produto das experiências em enfermagem clínica, na reflexão e na exploração destas experiências vivenciadas pelas autoras. Trata-se de uma teoria voltada para a prática, a qual propõe que as enfermeiras abordem a enfermagem de forma consciente e deliberadamente como uma experiência existencial. Preocupa-se com as experiências fenomenológicas vividas pelos indivíduos, buscando obter uma visão ampla do potencial do ser humano. Defendem que as sínteses das descrições fenomenológicas constroem e explicam a ciência de Enfermagem ${ }^{(5)}$.

Rosimarie Rizzo Parse criou a Teoria de enfermagem chamada "Homem-Vida- Saúde", sob influência dos princípios e conceitos de Rogers e trabalhos de Heidegger, Sartre e Merleau-Ponty na perspectiva do pensamento existencial-fenomenológico. Realizou a teoria como uma alternativa às práticas de Enfermagem, que na época eram voltadas ao modelo médico, demonstrando a importância de estudar o indivíduo como unidades vivas participativas, levando em consideração suas experiências nas situações de saúde e conferindo ao cliente o papel como principal responsável em fazer escolhas e tomar decisões que impliquem na mudança de saúde, baseados nas ciências humanas ${ }^{(6)}$. 
Jean Watson publicou sua teoria de enfermagem em 1988, denominada Teoria do Cuidado Transpessoal na qual o principal enfoque da enfermagem está nos fatores de cuidado que derivam da perspectiva humanística, combinados com a base de conhecimentos científicos. Defende que o cuidado pode auxiliar a pessoa a obter o controle, tornar-se versátil e promover as modificações na saúde baseado no sistema humanístico de valores que prevê autonomia, liberdade de escolha, com ênfase ao autoconhecimento e autocontrole ${ }^{(7)}$.

A Teoria das Transições proposta por Afaf I. Meleis teve influência do interacionismo simbólico e das ideias de Florence Nightingale. A teórica elenca sete razões pelas quais a transição deve ser considerada o foco da enfermagem uma vez que os enfermeiros auxiliam indivíduos e seus familiares na vivência de diversas situações e a lidar com a multiplicidade de alterações que essas situações ocasionam. Assim, define transição como um "processo complexo multidimensional que pode causar e afetar mudanças na vida, saúde, relacionamentos e meio ambiente ${ }^{\prime \prime(8: 359)}$.

Os componentes funcionais de uma teoria indicam uma descrição que analisa a relação das pressuposições com os conceitos e as proposições da teoria ${ }^{(3)}$. A análise desses componentes resulta em definições explícitas e implícitas, identificando na teoria avaliada o direcionamento do foco, oferecendo uma visão ampliada a cerca do problema de enfermagem e suas possíveis intervenções.

Nessa perspectiva, o Quadro 1 destaca a comparação entre componentes funcionais das teorias de enfermagem de Paterson e Zderad, Parse, Watson e Meleis a seguir, demonstra cada um dos componentes funcionais propostos pelos teóricos em cada perspectiva, de modo a possibilitar uma reflexão teórica comparativa das mesmas.

Analisando as propostas apresentadas pelas teóricas acerca do componente foco observase que Paterson e Zderard vislumbram este como uma relação dialógica e intersubjetiva, ao passo que Parse responsabiliza os indivíduos e famílias pela mudança nas suas práticas de cuidado. Para Watson o mesmo está ancorado na visão humanística do cuidado, mesclado com o conhecimento científico e para Meleis, as transições ocorridas ao longo da vida acarretam transformações individuais e consequente adaptação do cuidado.

Em relação ao componente cliente encontramse semelhanças entre Paterson e Zderad e Parse no sentido de que ambas acreditam na responsabilização dos seres humanos por suas escolhas e decisões proporcionando diferentes padrões de vida que influenciam na sua saúde. Nessa perspectiva, Meleis e Watson trazem a ideia de interação entre as partes, seja homem e ambiente, estabelecendo uma relação de proximidade entre os conceitos.

Para o componente saúde, as teóricas Paterson e Zderad, Parse e Meleis convergem no sentido de acreditar que saúde é resultado das experiências de vida, enquanto Watson vislumbra a saúde do ser humano como algo que transcende o físico para uma dimensão espiritual. Por fim, no que tange o componente ambiente, as teóricas expõem a inter-relação entre homem e ambiente, no sentido de interconectividade, exercendo influência no homem, seja interna ou externamente de modo a ocasionar uma relação de troca e evolução conjunta.

O Quadro 2 representa a análise comparativa dos componentes funcionais em relação às questões centrais sobre a Enfermagem, e revela que nas quatro teorias a definição de enfermagem é clara e explícita, destacando sua ação na perspectiva da promoção da saúde e da qualidade de vida. Contudo, enfatiza-se que Watson e Parse fortalecem a enfermagem como ciência, enquanto que Meleis e Paterson e Zderad enfocam a enfermagem como agente facilitador que auxilia o indivíduo para o alcance de melhores níveis de saúde.

As teorias oferecem insight no que concerne a intervenção de enfermagem, uma vez que esta se realiza através de um plano de cuidados adequado para melhor assistir à saúde do cliente, família e comunidade. Contudo, as quatro teóricas revelam a ideia de que o cuidado de enfermagem transcende as práticas e procedimentos de enfermagem, por depender da relação estabelecida entre profissional/paciente e reforçam que é necessário cuidar do indivíduo de forma global.

As teorias de Parse e Paterson e Zderad não oferecem uma ideia clara sobre os problemas de enfermagem, entretanto, em uma profundidade maior constata-se que assim como as outras duas teorias os problemas possuem origem no próprio ser humano. 
O componente funcional interação paciente/ enfermagem enfatiza a relação terapêutica existente entre enfermeira e paciente, nesse sentido as teorias possuem pressuposições básicas a esta relação como essência do propósito da enfermagem. A teoria do Cuidado Transpessoal e a teoria das Transições destacam fortemente que suas práticas acontecem a partir das interações entre paciente/enfermeiros, ao passo que na teoria Homem-Vida-Saúde a interação é ampliada e aplicada nas circunstâncias de crise e mudanças vivenciadas pelo indivíduo, família e comunidade, partindo inicialmente do enfermeiro $^{(9)}$.

Quadro 1 - Comparação entre componentes funcionais das teorias de enfermagem de Paterson e Zderad, Parse, Watson e Meleis. Florianópolis-SC, 2014

\begin{tabular}{|c|c|c|c|c|}
\hline \multirow{2}{*}{ Componentes } & \multicolumn{4}{|c|}{ Teoristas } \\
\hline & Paterson e Zderad & Parse & Watson & Meleis \\
\hline Foco & $\begin{array}{l}\text { Foco éa relação dialógica } \\
\text { intersubjetiva vivenciada } \\
\text { por seres humanos para } \\
\text { a utilização de seus } \\
\text { potenciais para estar } \\
\text { melhor }^{(5)} \text {. }\end{array}$ & $\begin{array}{l}\text { Foco é a orientação para } \\
\text { mudanças na prática da } \\
\text { enfermagem e direciona } \\
\text { as pessoas a participarem } \\
\text { como responsáveis do } \\
\text { cuidar de sua saúde }{ }^{(9)} \text {. }\end{array}$ & $\begin{array}{l}\text { O foco está nos fatores } \\
\text { de cuidado a partir da } \\
\text { perspectiva humanística } \\
\text { combinado com a base } \\
\text { de conhecimentos } \\
\text { científicos }^{(10)} \text {. }\end{array}$ & $\begin{array}{l}\text { O foco é facilitar as } \\
\text { transições que ocorrem } \\
\text { ao longo da vida, sendo } \\
\text { o conceito de transição } \\
\text { central para os cuidados } \\
\text { de enfermagem }{ }^{(8)} \text {. }\end{array}$ \\
\hline Cliente & $\begin{array}{l}\text { O cliente tem a } \\
\text { capacidade de conhecer } \\
\text { a si e ao seu mundo } \\
\text { interior, refletir, valorizar, } \\
\text { para vir a ser mais. } \\
\text { Os seres humanos } \\
\text { são considerados a } \\
\text { partir de uma estrutura } \\
\text { existencial que se dá } \\
\text { através de escolhas }{ }^{(5)} \text {. }\end{array}$ & $\begin{array}{l}\text { O cliente é o elemento } \\
\text { que comanda e o } \\
\text { principal responsável por } \\
\text { suas decisões. Assim, ele } \\
\text { determina as atividades } \\
\text { que irá modificar } \\
\text { em seus padrões de } \\
\text { vida e é orientado } \\
\text { pela enfermeira }{ }^{(9)} \text {. }\end{array}$ & $\begin{array}{l}\text { O cliente é valorizado } \\
\text { em si mesmo e para si } \\
\text { mesmo para ser cuidado } \\
\text { e auxiliado. Reflete a } \\
\text { visão filosófica de um } \\
\text { ser completamente } \\
\text { integrado, e é visto } \\
\text { como maior e diferente } \\
\text { que a soma das } \\
\text { partes }^{(10)} \text {. }\end{array}$ & $\begin{array}{l}\text { O cliente é um } \\
\text { ser humano com } \\
\text { necessida de s } \\
\text { específicas e que } \\
\text { interage com o } \\
\text { meio em que está } \\
\text { envolvido, e que } \\
\text { possui a capacidade } \\
\text { de se adaptar às suas } \\
\text { mudanças }{ }^{(8)} \text {. }\end{array}$ \\
\hline Saúde & $\begin{array}{l}\text { É definida como um } \\
\text { bem-estar e estar } \\
\text { melhor. O conceito de } \\
\text { saúde pressupõe que a } \\
\text { doença, pouco faz para } \\
\text { determinar a capacidade } \\
\text { que se tem para a } \\
\text { saúde. É um processo } \\
\text { de encontrar sentido } \\
\text { na vida, logo, a saúde } \\
\text { é experimentada no } \\
\text { processo de envolver- } \\
\text { se em cada momento }{ }^{(5)} \text {. }\end{array}$ & $\begin{array}{l}\text { É um processo de } \\
\text { "vir-a-ser", vivenciado } \\
\text { pelo homem e que se } \\
\text { inter-relaciona com } \\
\text { o ambiente. A saúde } \\
\text { consiste nas experiências } \\
\text { vividas. É um processo } \\
\text { de mudança contínua, } \\
\text { de transformação, } \\
\text { percebido por meio da } \\
\text { troca de energia com } \\
\text { as pessoas e com o } \\
\text { ambiente }{ }^{(9)} \text {. }\end{array}$ & $\begin{array}{l}\text { A saúde refere-se à } \\
\text { unidade e a harmonia } \\
\text { na mente, no corpo ena } \\
\text { alma. A saúde também } \\
\text { está associada com o } \\
\text { grau de congruência } \\
\text { entre o ser como } \\
\text { percebido e o ser como } \\
\text { apresentado }^{(10)} \text {. }\end{array}$ & $\begin{array}{l}\text { A saúde é mais do } \\
\text { que simplesmente } \\
\text { ausência de doença, } \\
\text { é a adaptação e a } \\
\text { manifestação da } \\
\text { consciencialização, } \\
\text { empoderamento e } \\
\text { controle sobre a vida, } \\
\text { e, quando ocorre o } \\
\text { desequilíbrio desses } \\
\text { elementos inicia-se o } \\
\text { processo detransição }{ }^{(8)} \text {. }\end{array}$ \\
\hline Ambiente & $\begin{array}{l}\text { Define que existem } \\
\text { dois ambientes em } \\
\text { que o ser humano } \\
\text { vive. O primeiro é } \\
\text { o interno, sendo ele } \\
\text { subjetivo, onde os } \\
\text { valores, as crenças e os } \\
\text { sentimentos se originam } \\
\text { e a reflexão permite } \\
\text { a percepção desses } \\
\text { sentimentos eo segundo } \\
\text { é o ambiente externo, } \\
\text { composto por objetos, } \\
\text { pessoas e coisas }{ }^{(5)} \text {. }\end{array}$ & $\begin{array}{l}\text { O a mbie nte é } \\
\text { construído a partir } \\
\text { das experiências } \\
\text { vividas pela pessoa. } \\
\text { O ser humano está } \\
\text { no a mbiente de } \\
\text { maneira conjunta e } \\
\text { simultânea. Relaciona } \\
\text { Homem-Vida-Saúde } \\
\text { com ambiente, ambos } \\
\text { participam na criação } \\
\text { um do outro e que } \\
\text { evoluem juntos }{ }^{(9)} \text {. }\end{array}$ & $\begin{array}{l}\text { O ambiente permite } \\
\text { o desenvolvimento do } \\
\text { potencial enquanto a } \\
\text { pessoa escolhe para } \\
\text { si a melhor ação em } \\
\text { determinado momento. } \\
\text { Considera que o } \\
\text { ambiente de cuidado } \\
\text { agradável melhora } \\
\text { o estado afetivo, } \\
\text { facilita as interações e } \\
\text { promove uma sensação } \\
\text { de satisfação(10). }\end{array}$ & $\begin{array}{l}\text { O ambiente é o } \\
\text { contexto onde o } \\
\text { indivíduo se insere e } \\
\text { que pode favorecer } \\
\text { para a concepção de } \\
\text { condições favoráveis de } \\
\text { transição, podendo ser, } \\
\text { a família, comunidade } \\
\text { e as condições físicas, } \\
\text { naturais e artificiais. } \\
\text { A interação com o } \\
\text { ambienteé influenciada } \\
\text { por fatores internos e } \\
\text { por fatores externos }{ }^{(8)} \text {. }\end{array}$ \\
\hline
\end{tabular}


Quadro 2 - Comparação entre os componentes funcionais das teorias de enfermagem de Paterson e Zderad, Parse, Watson e Meleis. Florianópolis-SC, 2014

\begin{tabular}{|c|c|c|c|c|}
\hline \multirow{2}{*}{ Componentes } & \multicolumn{4}{|c|}{ Teoristas } \\
\hline & Paterson e Zderad & Parse & Watson & Meleis \\
\hline Enfermagem & $\begin{array}{l}\text { É responsável por } \\
\text { desenvolver o bem estar } \\
\text { e atua na direção de } \\
\text { auxiliar nas escolhas do } \\
\text { enfermeiro, a partir de } \\
\text { necessidades percebidas. } \\
\text { O signifi cado da } \\
\text { enfermagem como ato } \\
\text { humano está no próprio } \\
\text { ato. Para entendê-lo é } \\
\text { necessário considerá-lo } \\
\text { "existente", um fenômeno } \\
\text { que ocorre no mundo real } \\
\text { das vivências humanas }{ }^{(5)} \text {. }\end{array}$ & $\begin{array}{l}\text { A enfermagemé definida } \\
\text { como uma ciência e } \\
\text { arte, fundamentada } \\
\text { nas ciências humanas } \\
\text { antes que nas ciências } \\
\text { naturais e que utiliza seu } \\
\text { conhecimento em prol } \\
\text { e a serviço das pessoas. } \\
\text { A meta da enfermagem } \\
\text { é a qualidade de } \\
\text { vida das pessoas }{ }^{(9)} \text {. }\end{array}$ & $\begin{array}{l}\text { A enfermagem é ciência } \\
\text { humana de pessoas e } \\
\text { experiências de saúde- } \\
\text { doença humanas que } \\
\text { são mediadas pelas } \\
\text { transações dos cuidados } \\
\text { profissionais, pessoais, } \\
\text { científicos, estéticos e } \text { éticos }^{(10)} \text {. }\end{array}$ & $\begin{array}{l}\text { É a profissão que } \\
\text { tem o maior contato } \\
\text { com quem é afetado } \\
\text { pela transição e está } \\
\text { preocupada com o } \\
\text { desenvolvimento, } \\
\text { p r o m o ç ã o e } \\
\text { recuperação dos } \\
\text { índivíduos. É o agente } \\
\text { que facilita a gerir a } \\
\text { transição e contribuir } \\
\text { para a manutenção e } \\
\text { promoção da saúde }{ }^{(8)} \text {. }\end{array}$ \\
\hline $\begin{array}{l}\text { Interação } \\
\text { Paciente- } \\
\text { Enfermagem }\end{array}$ & $\begin{array}{l}\text { A interação está centrada } \\
\text { no estar com o outro. } \\
\text { O sujeito-objeto, que } \\
\text { é possível conhecer } \\
\text { uma pessoa em sua } \\
\text { individualidade única, } \\
\text { já o sujeito-sujeito que é } \\
\text { quandoduaspessoasestão } \\
\text { abertas entre si de forma } \\
\text { plenamente humana }{ }^{(5)} \text {. }\end{array}$ & $\begin{array}{l}\text { Na interação paciente- } \\
\text { e n ferma ge m, o } \\
\text { enfermeiro é visto } \\
\text { como um professor e } \\
\text { agente de mudanças } \\
\text { que guia e orienta o } \\
\text { cliente e famílias }^{(9)} \text {. }\end{array}$ & $\begin{array}{l}\text { A interação parte } \\
\text { do principio que as } \\
\text { enfermeiras promovem } \\
\text { saúde quando formam } \\
\text { relacionamentos pessoa } \\
\text { a pessoa, em oposição } \\
\text { aos relacionamentos de } \\
\text { manipulação }\end{array}$ & $\begin{array}{l}\text { A interação paciente- } \\
\text { e n f e r m a g e m é } \\
\text { organizada em torno } \\
\text { de um propósito que } \\
\text { acarreta diversas } \\
\text { terapêuticas de } \\
\text { enfermagem para } \\
\text { promover, restaurar a } \\
\text { saúde }^{(8)} \text {. }\end{array}$ \\
\hline $\begin{array}{l}\text { Problemas de } \\
\text { Enfermagem }\end{array}$ & $\begin{array}{l}\text { A } \mathrm{s} \text { a } \mathrm{u} \mathrm{t} \text { o } \mathrm{r} \text { a } \mathrm{s} \\
\text { problematizam a prática } \\
\text { de enfermagem, por } \\
\text { meio dos pressupostos } \\
\text { da fenomenologia }{ }^{(5)} \text {. }\end{array}$ & $\begin{array}{l}\text { Um dos problemas } \\
\text { apresentados por Parse } \\
\text { seria na implicação } \\
\text { do uso do processo } \\
\text { de enfermagem, que } \\
\text { segundo ela, a prática de } \\
\text { enfermagem é criativa e } \\
\text { inovadora enãoestápresa } \\
\text { em regras prescritivas. } \\
\text { O pro c e s o de } \\
\text { enfermagem torna o } \\
\text { indivíduooufamília "fixos", } \\
\text { não sendo compatível } \\
\text { com sua teoria }{ }^{(9)} \text {. }\end{array}$ & $\begin{array}{l}\text { O problema consiste } \\
\text { não apenas na expressão } \\
\text { biofísica da doença, } \\
\text { mas também nas } \\
\text { dimensões psicofísicas } \\
\text { e psicossociais, isso } \\
\text { porque o sistema } \\
\text { de cuidado prevê a } \\
\text { criação de sistema de } \\
\text { valores humanístico, } \\
\text { fé e esperança, } \\
\text { relacionamento de } \\
\text { autoconfiança, expressão } \\
\text { de sentimentos }{ }^{(10)} \text {. }\end{array}$ & $\begin{array}{l}\text { Os problemas de } \\
\text { enfermagem são } \\
\text { visualizados como } \\
\text { sendo algo que insere } \\
\text { as estratégias de } \\
\text { cuidado na apreensão } \\
\text { da transição, a partir da } \\
\text { perspectiva de quem } \\
\text { a vivencia e propicia } \\
\text { a identificação das } \\
\text { necessidades para } \\
\text { o cuidado com essa } \\
\text { abordagem }{ }^{(8)} \text {. }\end{array}$ \\
\hline $\begin{array}{l}\text { Cuidados de } \\
\text { Enfermagem }\end{array}$ & $\begin{array}{l}\text { Tratam o cuidado de } \\
\text { enfermagem como } \\
\text { um encontro vivido } \\
\text { e dialogado, onde o } \\
\text { paciente e a enfermeira se } \\
\text { completam dentro deste } \\
\text { cuidado integral eholístico. } \\
\text { A enfermagem atua no } \\
\text { fortalecimento do bem } \\
\text { estar ea qualidade de vida. } \\
\text { Assim, enxerga além das } \\
\text { partes. Enquantocuidadora } \\
\text { tem a possibilidade de } \\
\text { conhecer o paciente } \\
\text { através do diálogo. } \\
\text { Cada ato de cuidar se } \\
\text { relaciona ao compartilhar. } \\
\text { Cada um participa da } \\
\text { situação de acordo } \\
\text { com seu modo de ser }{ }^{(5)} \text {. }\end{array}$ & $\begin{array}{l}\text { Sustentam-se em guiar } \\
\text { o ser humano, chamado } \\
\text { também como unidade } \\
\text { de vida, na escolha } \\
\text { das possibilidades } \\
\text { sobre o processo de } \\
\text { saúde, através de } \\
\text { uma participação } \\
\text { intersubjetiva com as } \\
\text { pessoas e famílias }{ }^{(9)} \text {. }\end{array}$ & $\begin{array}{l}\text { A formação de valores } \\
\text { humanístico-altruísta, } \\
\text { cultivo da fé, esperança } \\
\text { e sensibilidade, ajuda- } \\
\text { confiança, promoção } \\
\text { e a a ceit ção da } \\
\text { expressão de emoções. } \\
\text { A provisão de um } \\
\text { ambiente mental, físico, } \\
\text { social e espiritual }^{(10)} \text {. }\end{array}$ & $\begin{array}{l}\text { O cuidado de } \\
\text { enfermagem é o } \\
\text { núcleo de ação dos } \\
\text { enfermeiros, sendo o } \\
\text { processo facilitador } \\
\text { para transições bem } \\
\text { sucedidas, as quais } \\
\text { se caracterizam por } \\
\text { bem-estar emocional, } \\
\text { domínio e bem-estar } \\
\text { relacional }{ }^{(8)} \text {. }\end{array}$ \\
\hline
\end{tabular}




\section{CONSIDERAÇÕES FINAIS}

O conhecimento das teorias de enfermagem consolida a enfermagem enquanto profissão e ciência, uma vez que a articulação destes conhecimentos teóricos e a prática profissional promovem um cuidado de enfermagem de excelência $^{(4)}$. Construir essa reflexão comparativa proporcionou o aprofundamento acerca dos conceitos centrais das teorias e uma visão generalizada da relação entre os eventos do núcleo das mesmas.

Esta avaliação direcionou a adequação das teorias à ação de enfermagem e para o entendimento de como essa profissão pode interagir com o cliente/paciente/família no contexto em que estão inseridos, trazendo ideias de conectividade entre alguns componentes como ambiente, enfermagem e interação paciente-enfermagem.

Portanto, as reflexões teóricas deste estudo contribuem para avanços das ações de cuidado de enfermagem ao paciente em diversos momentos de sua vida, transições e/ou mudanças advindas no processo saúde-doença. Assim, a atenção especial ao cuidado humanizado, pautados em teorias, facilitam o processo de compreensão e visualização do ser humano e profissional de enfermagem como um todo.

\section{REFERÊNCIAS}

1. Braga GC, Silva JV. Teorias de Enfermagem. $1^{\mathrm{a}}$ ed. São Paulo: látria; 2011.

2. Garcia TR, Nóbrega MML. Contribuição das teorias de enfermagem para a construção do conhecimento da área. Rev. Bras. Enferm. [Internet] 2004;57(2) [acesso em 13 jun 2014]. Disponível: http://dx.doi.org/10.1590/ S0034-71672004000200019

3. Meleis AI. Theoretical nursing: development and progress. 5th ed. Philadelphia: Wolters Kluwer/ Lippincont Williams \& Wilkins; 2012.

4. Bousso RS, Poles K, Crus DALM. Conceitos e Teorias na Enfermagem. Rev. Esc. Enferm. USP. [Internet] 2014;48(1) [acesso em 13 jun 2014]. Disponível: http:// dx.doi.org/10.1590/S0080-623420140000100018

5. Paterson JG, Zderad LT. Enfermería humanística. México: Editorial Limusa; 1979. in practice and research. New York: Nacional league for nursing press; 1995.

7. Watson J. Art and aesthetics in nursing. New York: Nacional lengue for nursing press; 1994.

8. Meleis AI. Transitions Theory: Middle range and situation-specific theories in research and nursing practice. New York: Springer Publishing Company; 2010.

9. Lins GAI, Armendaris MK, Pinho DLM, Kamada I, Jesus CAC, Reis PED. Teoria de tornar-se humano na enfermagem ecológica: aplicando o método de avaliação de Meleis. Texto Contexto Enferm. [Internet] 2013;22(4) [acesso em 13 jun 2014]. Disponível: http:// dx.doi.org/10.1590/S0104-07072013000400037

10. Chistóforo BEB, Zagonel IPS, Carvalho DS. Relacionamento enfermeiro-paciente no préoperatório: uma reflexão à luz da teoria de Joyce Travelbee. Cogitare enferm. [Internet] 2006;11(1) [acesso em 19 jun 2015]. Disponível: http://dx.doi. org/10.5380/ce.v11i1.5977

6. Parse RR. Illuminations: The human becoming theory 